\title{
Infrasound measurements of debris flow
}

\author{
J. Hübl ${ }^{1}$, S. C. Zhang $^{2}$ \& A. Kogelnig ${ }^{1}$ \\ ${ }^{1}$ Institute of Mountain Risk Engineering, Department Civil Engineering \\ and Natural Hazards, University of Natural Resources \& Applied Life \\ Sciences, Vienna, Austria \\ ${ }^{2}$ Institute of Mountain Hazards and Environment, Chinese Academy of \\ Sciences and Ministry of Water Resources, Chengdu, China
}

\begin{abstract}
Processes such as wind, avalanches, traffic and debris flow are sources of subaudible sounds in the low frequency infrasonic spectrum. These signals have the ability to propagate kilometres from the debris flow source and provide a basis for developing wide area automated monitoring systems that can operate in locations unaffected by the process activity. This study focuses on naturally occurring infrasound produced by a 3 days debris flow event in July 2007, in the Jiangjia Gully, Yunnan, China. The debris flows had a big variety in terms of the amount of discharge and furthermore they differ from very fluid surges up to more solid surges with a density of $2000 \mathrm{~kg} / \mathrm{m}^{3}$. The data was monitored with two different microphones, a custom made Chinese Sensor and a standard infrasound measuring microphone from a German Company. Contemporary video recording and photographing took place for visual validation of the acoustic signals. The aim is to specify the debris flow signal out of environmental interferences through the use of digital filtering and frequency analysis.
\end{abstract}

Keywords: infrasound monitoring, debris flow, frequency spectrum, field study.

\section{Introduction}

Rapid mass movements like debris flows, debris floods and intensive bedload transport are periodic or episodic phenomena in alpine regions. Due to the fast socio-economic development of mountain regions, these processes which are at the intersection between the natural environment and the environment formed and controlled by human activities increasingly become a hazard for people and 
property. Though considerable research has been carried out in the last decades to understand processes like debris flows [1-3], there is still a lot unknown. This is partly due to the scarcity of observations and data of real events.

Infrasonic sound is too low frequent to hear; its acoustic spectrum covers frequencies below $20 \mathrm{~Hz}$ which are generated by the compressibility of the air. These low frequency signals have the ability to propagate long distances through the atmosphere with a velocity of $344 \mathrm{~m} / \mathrm{s}$ which is about the same as that of audible sound [4]. This is due to the low absorption of the air and the high reflectivity of the ground. Infrasound monitoring systems are used to detect hazards such as avalanches [5, 6, 8-10], landslides [7], nuclear explosions [11] and debris flows [4]. Debris flow generated infrasound signals are of significant amplitude and occupy a relatively noise free band in the low infrasonic spectrum $(8-12 \mathrm{~Hz})$. This study analysis and demonstrates characteristic infrasound signals of debris flow monitored during an event between the 25 and 30 July 2007 in the Jiangjia Gully, Yunnan, China. This work is possible due to cooperation with the Institute of Mountain Hazards and Environment of the Chinese Academy of Science and Ministry of Water Resources, with whom we share a database of infrasonic debris flow signals.

\section{Infrasound signals of debris flow}

The monitoring of natural mass movements is not always possible given the sporadic character of the events and the difficulty of accessing the affected areas and the bad weather conditions that usually accompany these phenomena. Monitoring systems based on seismic signals (frequency $30-80 \mathrm{~Hz}$; velocity $1000 \mathrm{~m} / \mathrm{s}$ ) are quite common and have been used to study debris flows for many years. Various previous studies on debris flow [e.g. 12-17] have already shown that it is possible to detect and monitor these processes with geophones and to distinguish them from other seismic sources. To overcome a major disadvantage of geophones in connection with debris flow, namely the limited spatial propagation of seismic waves, this study focuses on infrasonic signals. It is well known that a debris flow produces vibrations in the ground when it moves around a channel; these vibrations then produce sound waves, containing both audible sound $(20 \mathrm{~Hz}-20 \mathrm{kHz})$ and inaudible sound, infrasound, with frequencies less than $20 \mathrm{~Hz}$ [4]. Infrasound is expected to be generated by the violent surge front and the collision (or abrasion) between debris flow and the channel loose boundary [18]. In consequence, the analysis and inter comparison of the infrasound signals generated by various debris flows can provide useful information of these phenomena.

\section{Study site and monitoring system}

\subsection{Geographical and geological overview}

The catchment area of the Jiangjia Gully, Yunnan, China covers $48,6 \mathrm{~km}^{2}$. It is characterised by steep slopes, numerous areas of landslides and collapses, poor 
vegetation cover and intensive rainfall. The elevation level varies from $1050 \mathrm{~m}$ where the Jiangjia Ravine joins the Xiaojiang River up to $3145 \mathrm{~m}$, which is the highest point in the catchment, fig 1 . In this basin there are 154 gullies whose widths vary from narrow $50 \mathrm{~m}$ up to $200 \mathrm{~m}$ and with a variation in gradient from $20 \%$ to $60 \%$. The sediments for the debris flow are generated by landslides which supply the channel beds with materials. The mixture of sediments can be divided into two main classes: one is about $20 \mathrm{~mm}$ in mean diameter and the

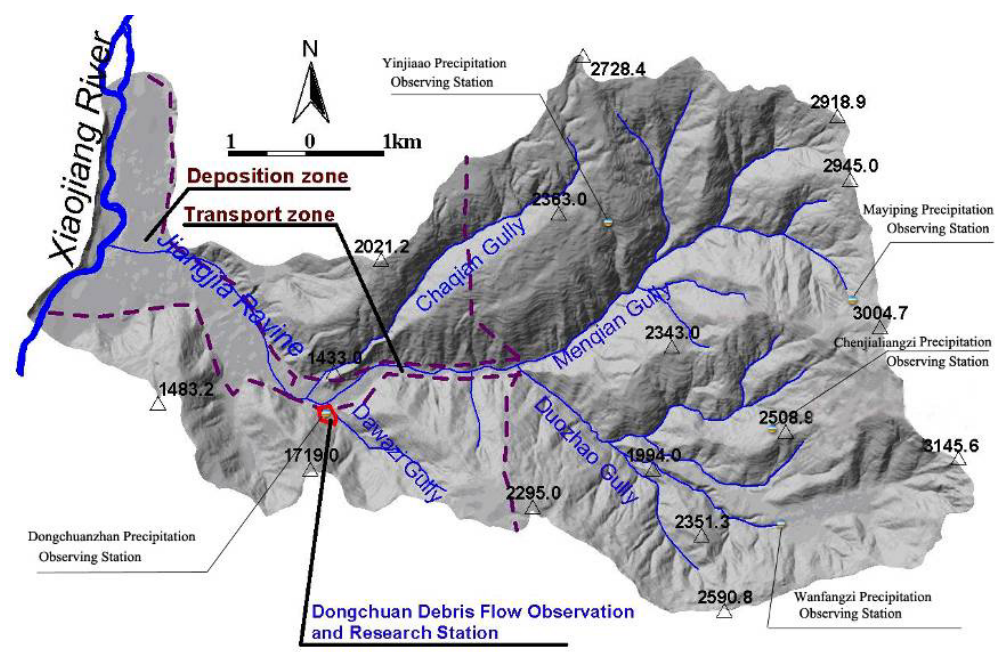

Figure 1: Overview of the Jiangjia Ravine (Source: IMHE).

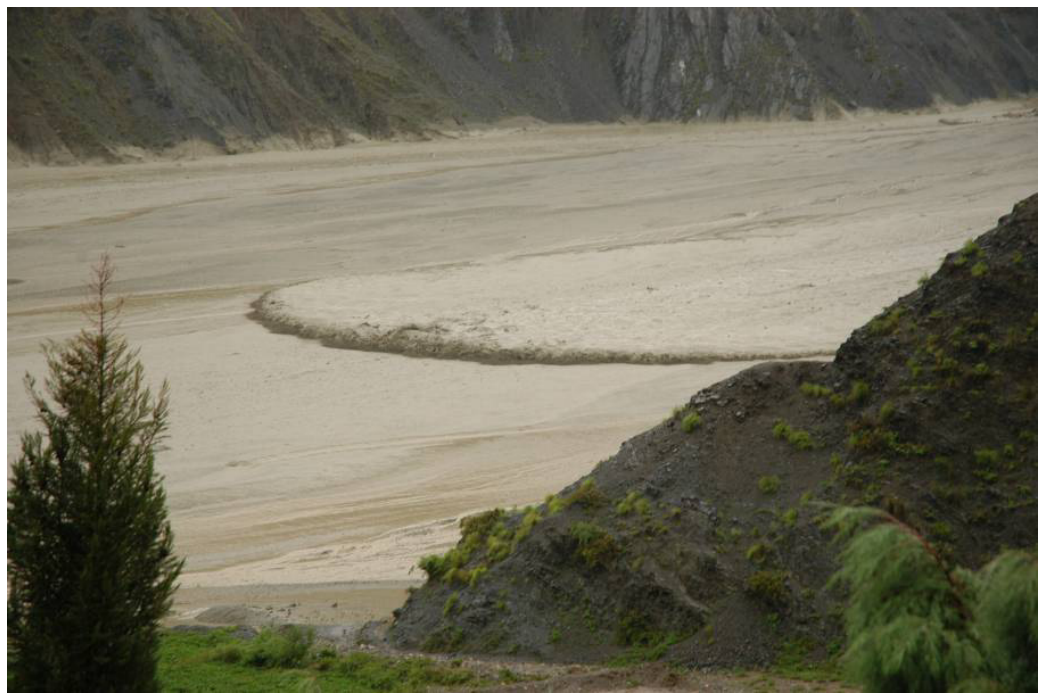

Figure 2: Debris flow surge passing the observation station. 
other is less than $2 \mathrm{~mm}$ [19]. These are easily eroded by the water stream after a rainfall. The correlation between the occurrence of debris flow and 10-minute rainfall is very good and moreover, debris flow occurs when rainfall intensity increases and does not when intensity decreases [19]. The characteristics of the processes occurring in the Jiangjia Ravine can be described as wave trains of debris flow occurring for a period of time without any surges in between. Shortest burst last 10 to 20 minutes but big events can hold up to 10 hours.

Looking at the height of such a surge it can be up to $3 \mathrm{~m}$ in the wide river bed with the biggest velocities at the tongue-like head $(5-10 \mathrm{~m} / \mathrm{s})$. Due to these facts the area is perfect for debris flow monitoring purposes.

\subsection{Infrasound Monitoring Station (IMS)}

One of the most successful studies was carried out by Zhang [4]. He developed an infrasound warning system (DFW-I Model) and applied it successfully to detect over 60 debris surges in Jiangjia Gullies (China) with a warning time of 10-30 minutes.

During the events in July 2007 the data was monitored with two different microphones: The DFW-I III Model, custom made by our Chinese partners and the WME $960 \mathrm{H}$, a German made standard infrasound measuring microphone. Both sensors are based on the capacitive pressure transducer principle and have similar specifications; characterised by a sensitivity of $50 \mathrm{mV} / \mathrm{Pa}$, wide frequency response $(3-100 \mathrm{~Hz})$ and wide dynamic range $(150 \mathrm{~dB})$.

\subsection{Data analysis}

The methodologies adopted for data analysis include the Fast Fourier Transformation and the Continuous Wavelet Transform (CWT). Traditionally, the Fourier Transformation has been the general approach to analyze signal data in frequency domain for investigating its energy frequency distribution [20, 21]. The demand of FFT is system linearity, periodicity and stationarity; unfortunately most data monitored from natural phenomena do not fulfill this requirement. Therefore spurious harmonic components are induced that cause energy spreading and mislead the energy-frequency distribution for nonlinear and non-stationary data.

The Continuous Wavelet Transform (CWT) is used to decompose a signal into wavelets, small oscillations that are highly localized in time. Whereas the Fourier transform decomposes a signal into infinite length sins [22] and cosines, effectively losing all time-localization information, the CWT's basis functions are scaled and shifted versions of the time-localized mother wavelet. The CWT is used to construct a time-frequency representation of a signal that offers very good time and frequency localization e.g. [23, 24].

\section{Results and discussion}

The results shown below have been monitored on the 25.07.2007. To compare and evaluate the signals, they have been recorded simultaneously with two 
infrasound sensors. On this day, especially in the time between 12.30am and $1.20 \mathrm{pm}$, regular debris flow was observed. The data is representing a time gap of 30 seconds where various surges occurred. In the following figures the top blue graph is data monitored with the Gefell Mk 222 infrasound sensor and the bottom green graph is data monitored with the China Mk 224 sensor.

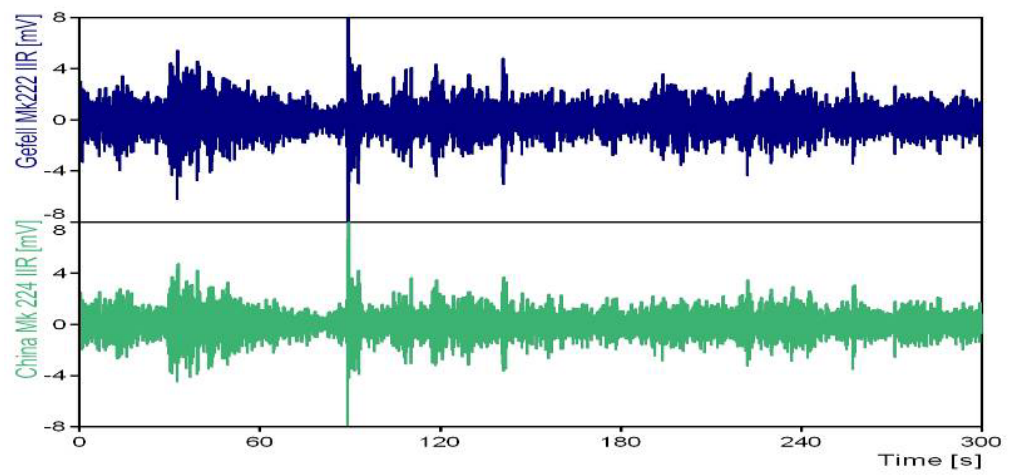

Figure 3: Raw data of debris flow during flow event (25.07.2007).

Data were recorded with a sampling frequency of $100 \mathrm{~Hz}$. The predominant frequency, as it appears in figure 5 , is around $10 \mathrm{~Hz}$. There is another peak around $30 \mathrm{~Hz}$, which is not in the infrasonic range. As figures 4 and 5 illustrate, there are strong correlations throughout the whole analysis between the two different sensors. The following spectra were calculated using both the FFT and the CWT algorithms.

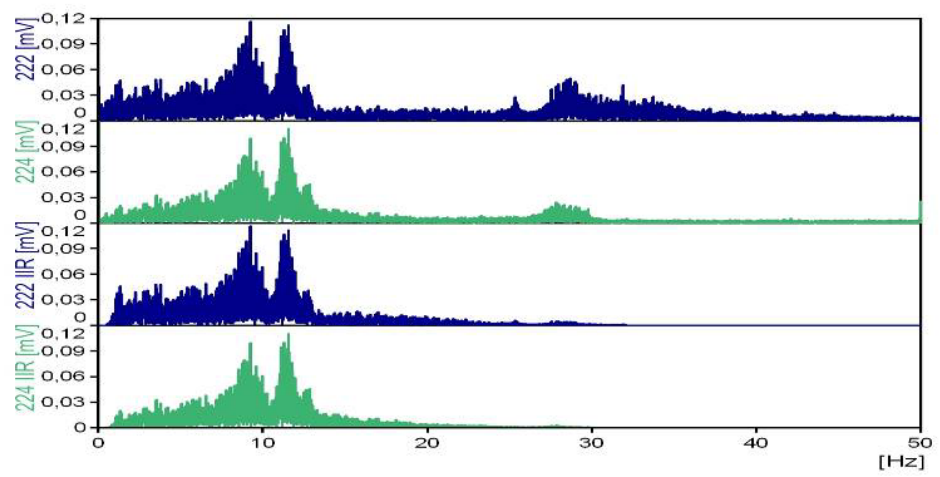

Figure 4: $\quad$ Frequency spectrum of the unfiltered (top) and filtered signal (bottom).

The spectra prove, no matter if FFT or CWT analysis, that infrasonic sound is emitted by debris flow. The signals possess a predominant frequency around $10 \mathrm{~Hz}$. It is also possible to detect different surges passing the sensor. 
8 Monitoring, Simulation, Prevention and Remediation of Dense Debris Flows II

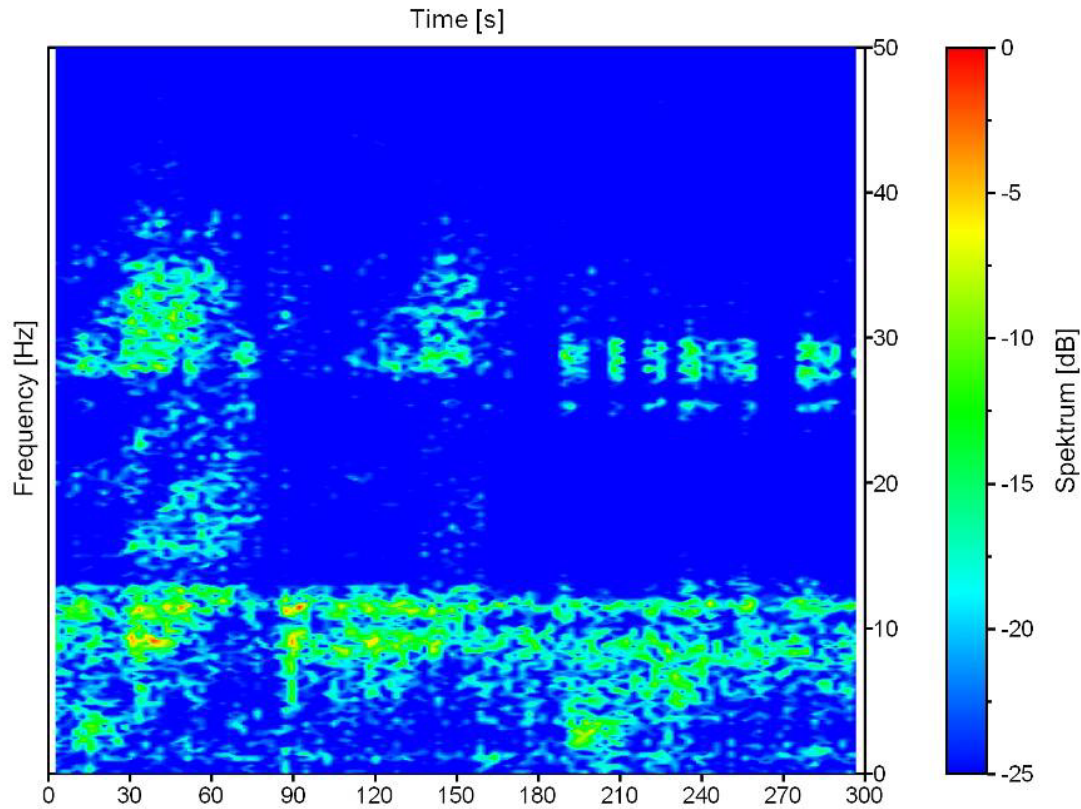

Figure 5: $\quad$ FFT spectra of unfiltered data recorded by Mk 222.

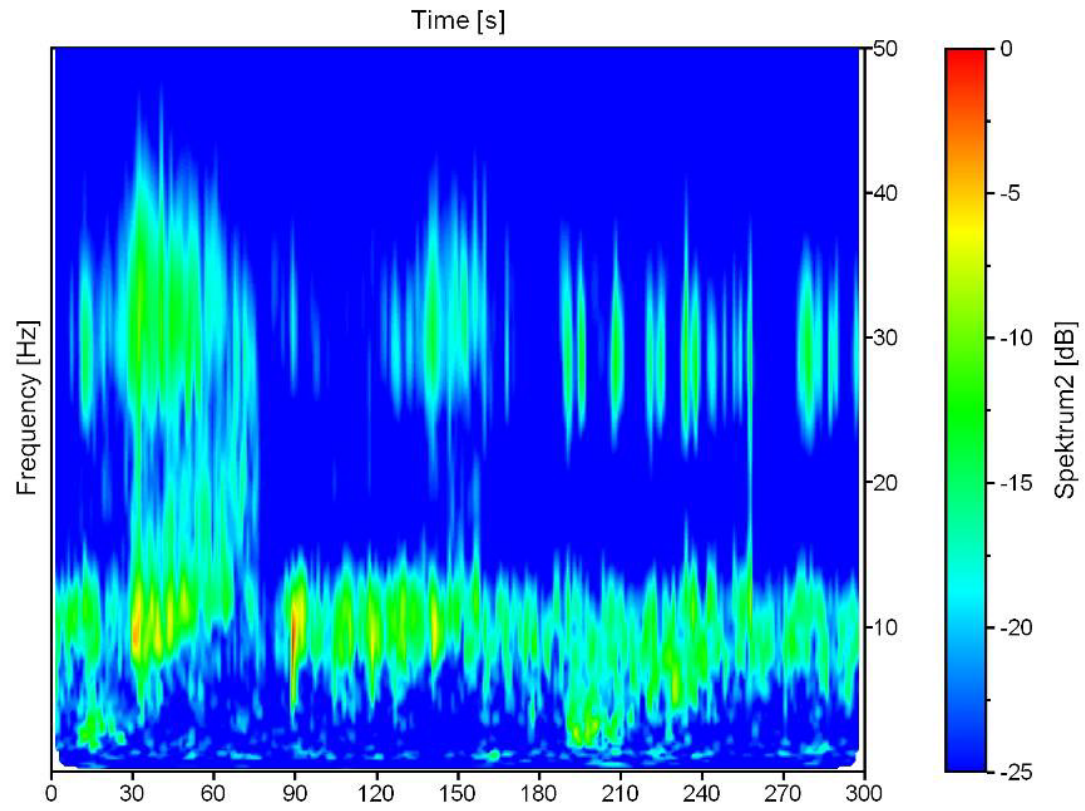

Figure 6: CWT spectra of unfiltered data recorded by Mk 222. 
Monitoring, Simulation, Prevention and Remediation of Dense Debris Flows II 9

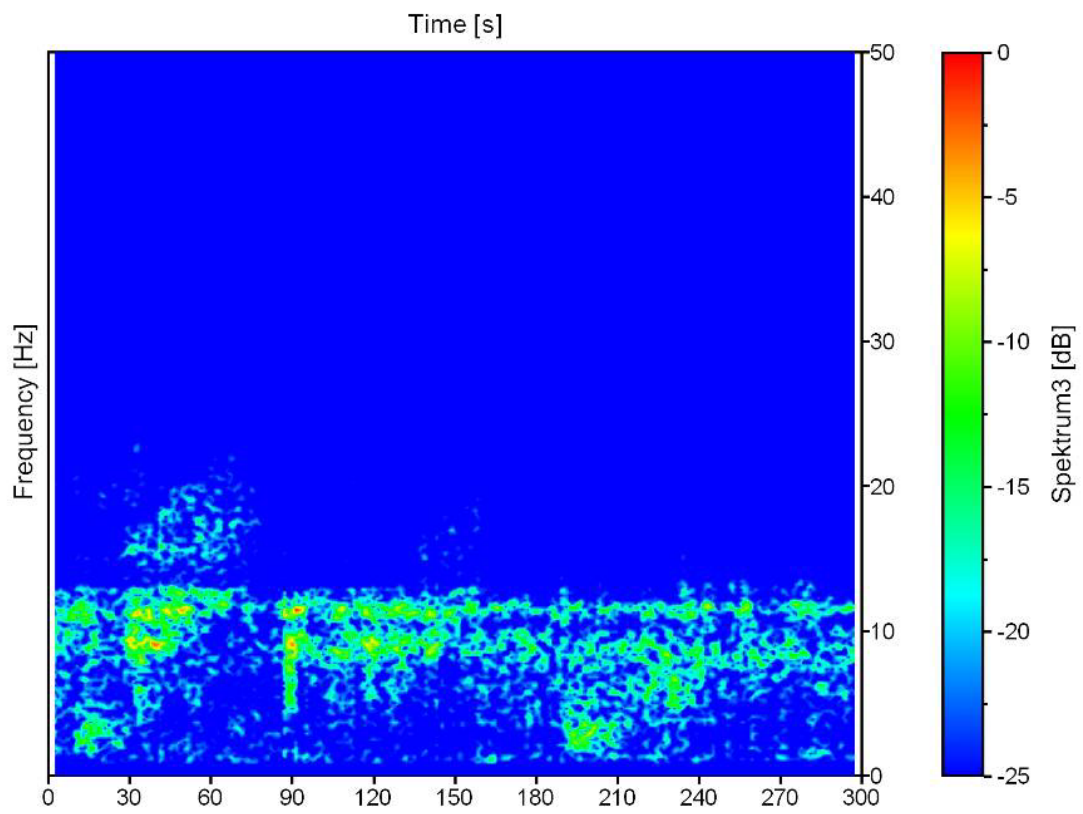

Figure 7: $\quad$ FFT spectra of filtered data recorded by Mk 222.

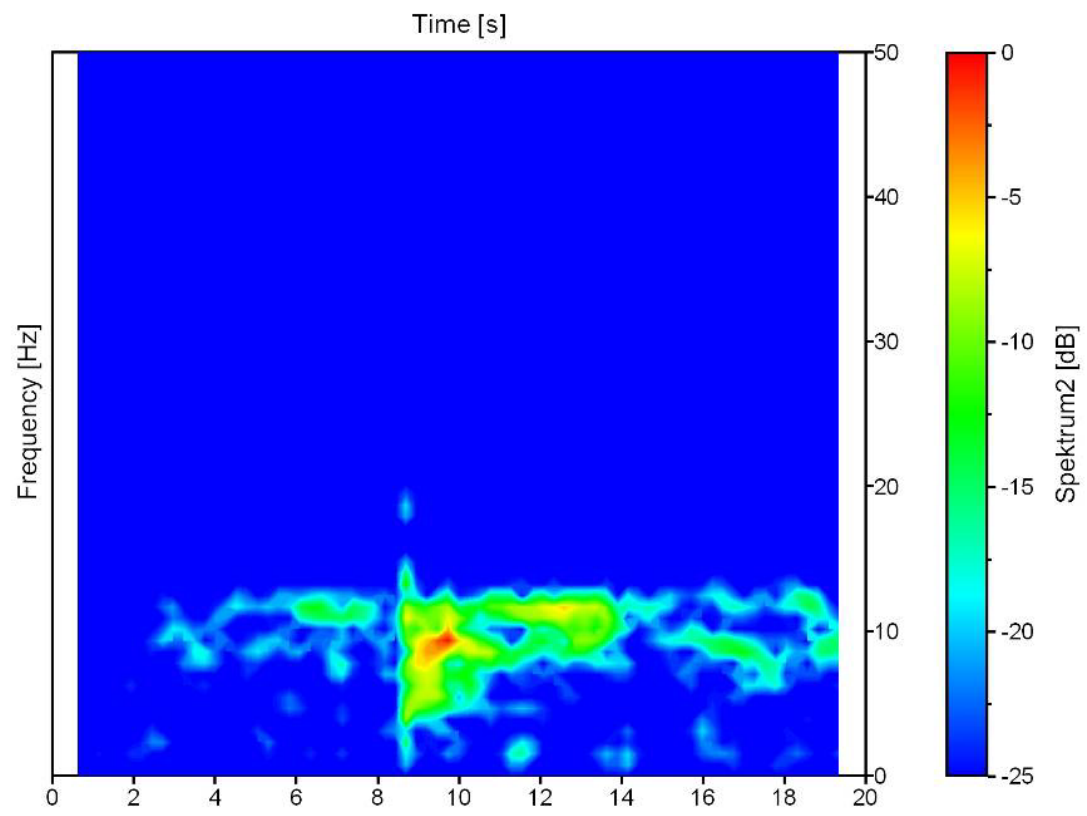

Figure 8: $\quad$ FFT spectra of filtered data of a single surge recorded by Mk 222. 
In order to decrease the influence of interfering noise, filtering was applied to the collected data. The filtering, in the range from $1-20 \mathrm{~Hz}$, was done by a fourth order Butterworth band pass filter. The results clearly demonstrate that it was possible to remove the acoustic signals of debris flow around $30 \mathrm{~Hz}$. Although we expected improvement of signal intensity in the infrasonic range it did not occur. This could be explained by the low interfering infrasonic noise existing in the Jiangjia Ravine.

Figure 9 shows a time sequence (seconds 80-100) of the previous discussed data. Through the FFT analysis the relationship between the frequencies of peak intensity and a single surge is shown in figure 9. The greater the discharge of a debris flow the higher is the amplitude of the signal and predominant frequency varies within a bigger range. As the surge passes the observation station, the energy with the frequencies between $5-15 \mathrm{~Hz}$ is intensified. Moving further away peak frequencies tend to concentrate around $10 \mathrm{~Hz}$.

\section{Summary and conclusions}

Infrasound produced by debris flow is explored in this study by examining field data monitored in Jiangjia Gully, Yunnan, China. The signal shows two peaks, one in the infrasound range, around $10 \mathrm{~Hz}$, and another one around $30 \mathrm{~Hz}$. More signal intensity is produced in the infrasonic spectrum. It is also possible to detect a single surge passing the observation station. Therefore it can be used to detect and record debris flow for warning and for research purposes. Furthermore other natural disasters and phenomena produce infrasonic signals as well [4]. Thus it is needed to distinguish them from debris flow before.

\section{References}

[1] Iverson, R.M. The physics of debris flows. Reviews of Geophysics 35(3) (1997), pp.245-296.

[2] Iverson, R.M., The debris-flow rheology myth. In: Rickenmann D, Chen CL (eds.): Debris-Flow Hazards Mitigation: Mechanics, Prediction, and Assessment; Proceedings of the $3^{\text {rd }}$ International DFHM Conference Davos Switzerland September 10-12 2003, Millpress, Rotterdam, pp. 303-314, 2003.

[3] Ancey, C., Debris Flows and Related Phenomena. In: Balmforth, N.J.; Provenzale, A. (eds): Geomorphological Fluid Mechanics. Lecture Notes in Physics (LNP) 582, pp. 528-547, (2001).

[4] Zhang S., Hong Y., Yu B., Detecting infrasound emission of debris flow for warning purpose, 10 Congress Interpraevent, pp. 359-364, 2004.

[5] Bedard A.J., Detection of avalanches using atmospheric infrasound, Proceedings; Western Snow Conference, Fort Collins, CO, 1989.

[6] Bedard A.J., An evaluation of atmospheric infrasound for monitoring avalanches, Proceedings; $7^{\text {th }}$ International Symposium on Acoustic Sensing 
and Associated Techniques of the Atmosphere and Oceans, Boulder, CO, 1994.

[7] Bedard A.J., Infrasonic and near infrasonic atmospheric sounding and imaging, NOAA/EARL/Environmental Technology Laboratory, 1996.

[8] Scott E.D., Lance C., Infrasonic monitoring of avalanche activity, Proceedings; International Snow Science Workshop, Penticton, British Columbia, 2002.

[9] Scott E.D., Results of recent infrasound avalanche monitoring studies, Proceedings; International Snow Science Workshop, Jackson Hole, Wyoming, 2004.

[10] Scott E.D., Practical implementation of avalanche infrasound monitoring technology for operational utilization near Teton Pass Wyoming, Proceedings; International Snow Science Workshop, 2006.

[11] Christie D. R., Vivas Veloso J. A., Campus P., Bell M., Hoffmann T., Langlois A., Martysevich P., Demirovic E., Carvalho J., Detection of atmospheric nuclear explosions : the infrasound component of the International monitoring system, Journal Kerntechnik, Monitoring the Nuclear-Test-Ban, vol. 66, no 3 (20 ref.), pp. 96-101, 2001.

[12] Okuda S., Okunishi K., Suwa H., Observation of debris flow at Kamikamihori Valley of Mt. Yakedade, Excursion Guidebook of the Third Meeting of IGU commission on Field Experiment in Geomorphology, pp127-130, 1980.

[13] Wu J., Kang Z., Tian L., Zhang S., Observation and investigation of debris flows at Jiangjia Gully in Yunnan Province (China), Sci. Press, Beijing, 1990.

[14] Hadley K., Lahusen R., Deployment of an acoustic flow monitor system and examples of its application at Mount Pinatubo, Philippines (abstract), Eos Trans. $A G U, 72(44), \mathrm{F} 67,1991$.

[15] Marchi L., Arattano M., Deganutti A., Ten years of debris-flow monitoring in the Moscardo Torrent (Italian Alps), Geomorphology, 46(1-2), 1-17, 2002.

[16] Arattano M., Monitoring the presence of the debris-flow front and its velocity through ground vibrations detectors, Proceedings of the Third International Conference on Debris-Flow Hazards Mitigation: Mechanics, Prediction and Assessment, Millpress, Rotterdam, Vol.2, pp731-743, 2003.

[17] Huang, C.-J., H.-Y. Yin, C.-Y. Chen, C.-H. Yeh, And C.-L. Wang, Ground Vibrations produced by rock motions and debris flow, J. Geophys. Res., 112, F02014, doi:10.1029/2005JF000437, 2007.

[18] Chou H.T., Cheung Y.L., Zhang S. C., Calibration of infrasound monitoring systems and acoustic characteristics of debris-flow movements by field studies, Institute of Mountain Hazards and Environment, Chinese Academy of Science and Ministry of Water resources, 2007.

[19] Takahasi T., Debris Flow, International association for hydraulic research (IAHR), 1991.

[20] Percival D.B., Walden A.T., Spectral Analysis for Physical Applications, Cambridge Academic Press, 1998. 
12 Monitoring, Simulation, Prevention and Remediation of Dense Debris Flows II

[21] Smith S. W., The Scientist and Engineers Guide to Digital Signal Processing, California Technical Publishing, 1997.

[22] Grosse C, Ruck Hj, Bahr G., Analyse von Schallemissionssignalen unter Verwendung der Wavelet-Transformation 13. Kolloquium Schallemission, Jena 2001

[23] Eric D. Ryan, Joel T. Cramer, Alison D. Egan, Michael J. Hartman and Trent J., A real-time earthquake detector with prefiltering by wavelets Computers \& Geosciences, Volume 29, Issue 7, pp. 911-919, 2003.

[24] F. Botella, J. Rosa-Herranz, J. J. Giner, S. Molina and J., Time and frequency domain responses of the mechanomyogram and electromyogram during isometric ramp contractions: A comparison of the short-time Fourier and continuous wavelet transforms, Journal of Electromyography and Kinesiology, Volume 18, Issue 1, Pages 54-67, 2003. 